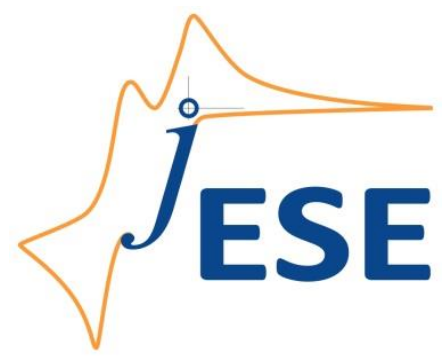

Open Access: ISSN 1847-9286

www.jESE-online.org

Original scientific paper

\title{
Recovery of nickel from spent NiCd batteries by regular and ultrasonic leaching followed by electrodeposition
}

\author{
Elumalai Selvamani Nivetha, Ramanujam Saravanathamizhan ${ }^{\square}$ \\ Department of Chemical Engineering, A.C.Tech Campus, Anna University, Chennai-600 025, India
}

Corresponding author: ${ }^{凶}$ thamizhan79@rediffmail.com, rsthamizhan@gmail.com, Tel: +91 4422359237

Received: September 6, 2018; Revised: July 17, 2019; Accepted: July 17, 2019

\begin{abstract}
This study focuses on the hydrometallurgical route of separating Ni metal from spent nickel cadmium (NiCd) batteries. The comparison of separation of nickel metal with the assistance of ultrasonic leaching and regular leaching was performed. Sulphuric acid (solvent) was used as the lixiviant to leach out the nickel metal ions from the spent battery and the parameters affecting the leaching with and without ultrasonication were optimized. The major parameters affecting the leaching process are volume of solvent, concentration of lixiviant and leaching time. The electrodeposition of nickel metal ions from ultrasonically assisted and regular leaching was carried out at an optimized current density of $8 \mathrm{~A} \mathrm{dm}^{-2}$, contact time of 4 hours and the concentration of lixiviant of $5 \mathrm{M}$. It was observed that the recovery efficiency for ultrasonically assisted leaching followed by electrodeposition is $98.5 \%$, while in regular leaching followed by electrodeposition is $90.8 \%$.
\end{abstract}

\section{Keywords}

Electrodeposition; leaching; spent battery; ultrasonication

\section{Introduction}

Rechargeable batteries such as nickel cadmium ( $\mathrm{NiCd}$ ), nickel metal hydride ( $\mathrm{NiMH}$ ) and lithium ion batteries are commonly used as the power sources in electronic devices like mobile phones, computers, digital cameras, and hybrid electric vehicles [1]. Generally, batteries are complex systems containing large number of different materials inside a small volume. All materials in a battery contribute to environmental pollution when discarded [2,3].

In NiCd battery, the anode is nickel oxy-hydroxide, the cathode is cadmium and the electrolyte is $\mathrm{KOH}$. The nickel content of the cathodic part is $69.26 \%$, which represents a significant amount to be recovered. There are two major techniques carried out in the recovery of metals, namely the hydrometallurgical process and the pyrometallurgical process. Hydrometallurgical process includes solvent extraction, acid or base leaching, sequential leaching along with electrodeposition or selective precipitation, bio-leaching and ultrasonic assisted leaching [4-8]. 
Innocenzi and Veglio [9] described two sequential leaching steps followed by selective precipitation of rare earths from $\mathrm{NiMH}$ batteries. Leaching was carried out with sulphuric acid as the lixiviant and three major parameters were studied, i.e. concentration of sulphuric acid, temperature and concentration of citric acid. They showed that citric acid promotes efficient leaching of metals acting as a reducing agent. The selective precipitation of metals was carried out using $5 \mathrm{M} \mathrm{NaOH}$. Rare earths were precipitated as sulphates and it was observed that $99 \%$ of rare earths were recovered after selective precipitation. Tanong et al. [10] demonstrated a hydrometallurgical route to recover metals from a mixture of various spent battery samples. Box-Behnken design was used to optimize various factors that influence the metal removal process. Eight leaching reagents were used to leach the metals at various concentrations and temperatures and sulphuric acid was found the most effective. It is reported that to recover the maximum amount of metal, the optimum values are $1 \mathrm{M}$ sulphuric acid concentration, fixed solid/liquid ratio of $18 \% \mathrm{w} / \mathrm{w}$ and $30 \mathrm{~min}$ of leaching time.

One of the key technologies in the recovery of metals prevailing in the current scenario is ultrasonically assisted leaching. The resulting small particle size would increase the surface area and promote a higher rate of diffusion of solvent through convective motion [11,12]. Xin et al. [13] have reported the leaching kinetics of $\mathrm{Zn}$ with other metals using ultrasound and evaluated effects of major factors such as temperature, sulphuric acid concentration, solid/liquid ratio and ultrasound power. It was reported that $80 \%$ of $\mathrm{Zn}$ was recovered using ultrasonic leaching. Li et al., [14] studied recovery of $\mathrm{Co}$ and $\mathrm{Li}$ from spent lithium-ion batteries using ultrasound assisted leaching. The author reported that more than $96 \%$ Co and $100 \%$ Li were recovered using ultrasound assisted citric acid leaching. A combined technique of electro-assisted leaching and electrodeposition of metals from spent NiCd batteries was investigated by Hazottee et al. [15]. In this investigation expanded platinized titanium was used as anode, and an aluminium plate as cathode. A cell voltage in the range of 6-10 V led to a highly selective deposition of cadmium from nickel and cobalt. Tudela et al. [16] studied the ultrasonic effect on electrodeposition of nickel and the effect of ultrasonic power on the characteristics of the thin coating. The ultrasonic assisted electrodeposition was carried out in the ultrasonicator bath with an operating frequency of $33 \mathrm{kHz}$. It was observed that the application of ultrasound led to the change in orientation of the $\mathrm{Ni}$ deposit. Santos et al. [17] studied chemical and electrochemical recycling methods for $\mathrm{Ni}, \mathrm{Co}, \mathrm{Zn}$ and $\mathrm{Mn}$ from the positive electrode of spent $\mathrm{NiMH}$ batteries.

The objective of the present study is to recover nickel from spent NiCd batteries using ultrasonic leaching followed by electrodeposition. NiCd batteries were manually dismantled to identify the various components and the cathode was characterized using atomic absorption spectroscopy (AAS). The major factors that affect the leaching and electrodeposition such as concentration of sulphuric acid, amount of solvent required, leaching time and current densities were optimized. Selective electrodeposition of $\mathrm{Ni}$ was performed at a constant cell potential of $2.6 \mathrm{~V}$.

\section{Materials and methods}

\section{Dismantling of spent batteries}

Four samples of NiCd rechargeable battery with specifications of $700 \mathrm{mAh}$, AA size and $1.2 \mathrm{~V}$ were collected from various electronic devices and toys. The spent batteries were manually dismantled using a saw and knife to identify various components present. These components presented in wt.\% were: a paper insulation (15 wt.\%), black mass (cathode) (17 wt.\%), anode (29.23 wt.\%), cathode cap and metal outer casing (34.54 wt.\%), washer and a plastic outer cover (3.95 wt.\%). Material balance was done to account for the amount of each component present. 


\section{Characterization of cathode part}

The cathode part of the spent battery was characterized with the aid of AAS. The metal components present in the cathode part and their wt.\% contents are shown in the Table 1. Obviously, $\mathrm{Ni}$ is present at about $70 \mathrm{wt} . \%$ of the total cathode part of the sample.

Table 1. Characterization of cathode part of the spent NiCd battery

\begin{tabular}{ccc}
\hline Sample No & Metal component & Content, wt.\% \\
\hline 1 & $\mathrm{Ni}$ & 69.26 \\
\hline 2 & $\mathrm{Cd}$ & 22.14 \\
\hline 3 & $\mathrm{Co}$ & 0.62 \\
\hline 4 & $\mathrm{Fe}$ & 0.61 \\
\hline 5 & $\mathrm{Zn}$ & 0.49 \\
\hline 6 & $\mathrm{Mg}$ & 0.002 \\
\hline 7 & Other metals & 6.82 \\
\hline
\end{tabular}

\section{Leaching of black mass}

In the bath type ultrasonic generator a standard electricity line of $50 \mathrm{~Hz} \mathrm{AC}$ supply is converted to an ultrasonic frequency through in-built piezoelectric transducer. The sonicator generates a constant frequency of $33 \mathrm{kHz}$ for the constant power input. It consists from a rectangular bath type with cooling water circulation to maintain the temperate in the bath. About $0.5 \mathrm{~g}$ of the cathode part of battery sample was taken for the leaching. In regular leaching, the mixture of sulfuric acid and battery powder was kept suspended with the aid of magnetic stirrer. The leaching was performed with different volumes of sulfuric acid as the lixiviant under various operating conditions. Regular leaching and ultrasonic assisted leaching were carried out for 4 hours at various concentrations of sulfuric acid $(3,4,5,6$ and $7 \mathrm{M})$.

\section{Electrodeposition of nickel}

Electrodepostion was carried out using stainless steel electrodes as anode and cathode, each having dimensions of $12.5 \times 6 \mathrm{~cm}$ in a setup shown schematically in Figure 1 .

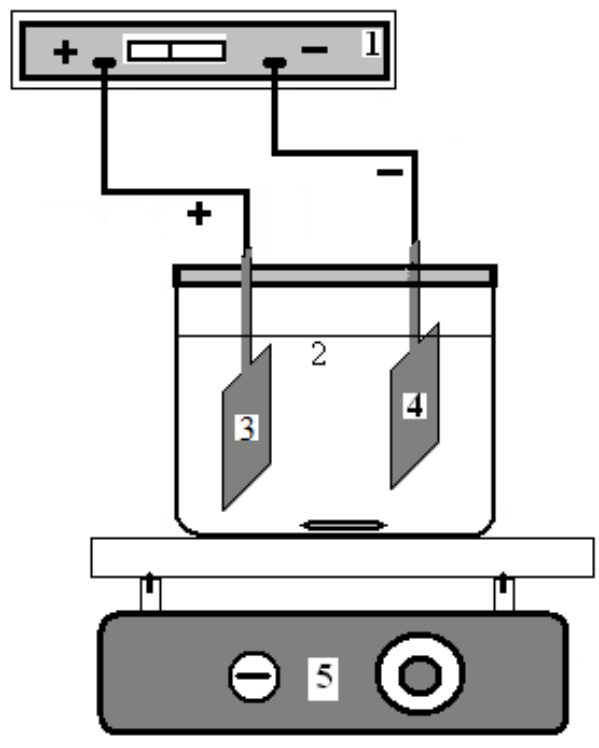

Figure 1. Schematic representation of electrode position setup: 1-regulated power supply, 2-glass vessel with leachate solution, 3-anode, 4-cathode and 5-magnetic stirrer

The electrodes were kept $2 \mathrm{~cm}$ apart. The electrolysis was carried out with the leachate from the regular and ultrasonically assisted leaching as the electrolyte at a current density of $8 \mathrm{~A} \mathrm{dm}^{-2}$ through a time period of 4 hours. 
The recovery efficiency is calculated by the Equation (1):

Recovery, \% $=\left(\left(C_{0}-C_{\mathrm{t}}\right) / C_{0}\right) \cdot 100$

In Eq. (1), $C_{0}$ is initial concentration of nickel $(\mathrm{ppm})$ and $C_{\mathrm{t}}$ is concentration of nickel (ppm) present in leachate after time $(t)$.

\section{Results and discussion}

\section{Leaching}

The effect of sulfuric acid concentration on regular and ultrasonically assisted leaching is shown in Figure 2. The increase in acid concentration increases the dissolved concentration of nickel metal ions in the medium. This is because higher is the concentration of sulfuric acid, higher will be the generation of protons by acid dissociation, facilitating thus production of metal ions to the solution. The maximum dissolution concentration of nickel metal ions was achieved at about $5 \mathrm{M}$ of sulfuric acid. By keeping the concentration constant at $5 \mathrm{M}$, the leaching was performed at various time intervals from one hour to 5 hours at room temperature $\left(32^{\circ} \mathrm{C}\right)$ as shown in Figure 3 . The increase in the time period increases the contact time of the solution and the battery sample so that the dissolution takes place effectively. The maximum dissolution concentration of nickel metal ions is obtained for a time period of 4 hours.

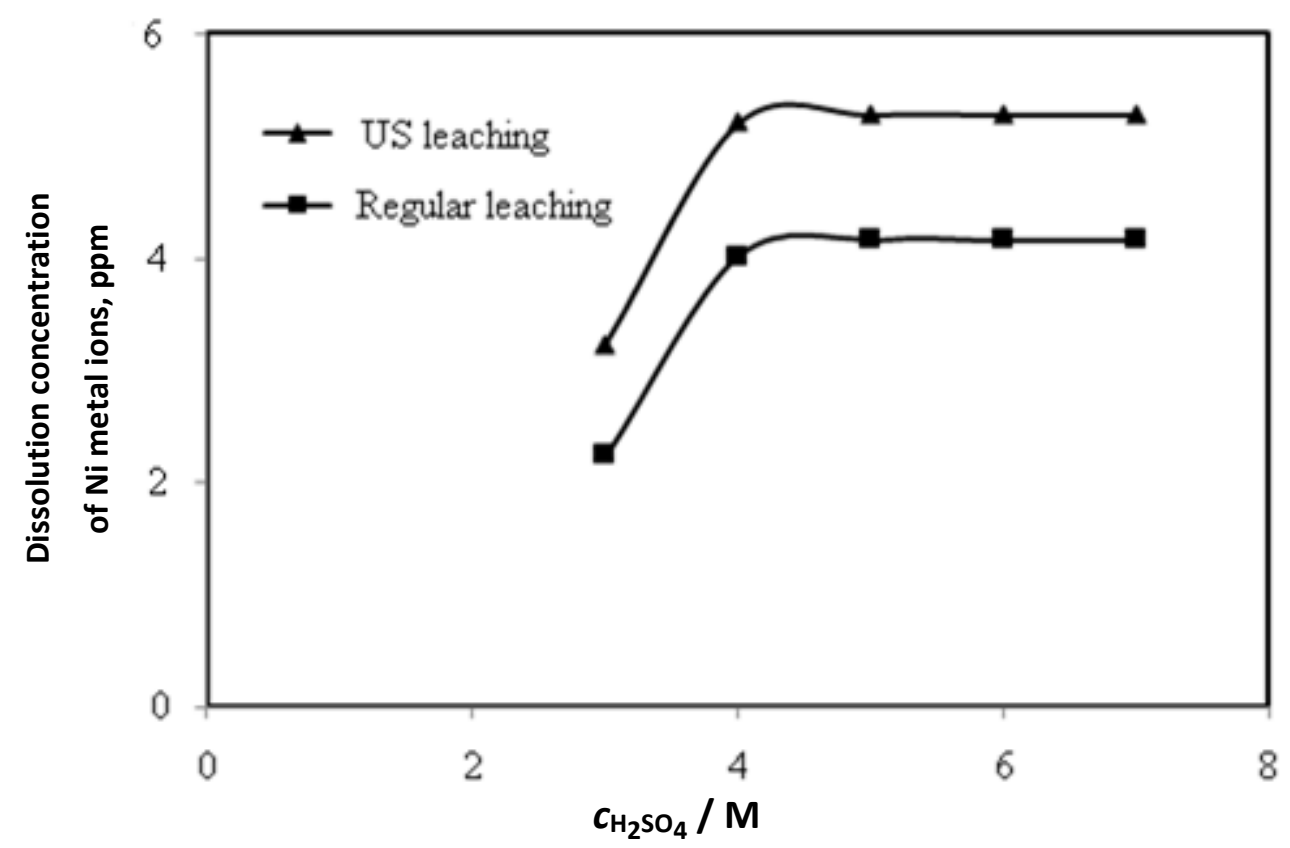

Figure 2. Effect of sulfuric acid concentration on Ni dissolution. Solvent volume $60 \mathrm{ml}$, leaching time $4 \mathrm{~h}$

As shown in Figure 4, the amount of required lixiviant is obviously a major factor that affects the dissolution of nickel metal ions.

Initially $15 \mathrm{ml}$ of sulfuric acid was taken to leach out the metal ion which was sufficient enough to submerge the battery sample. Doubling the sulfuric acid produced an increase in the concentration of nickel ions, and maximum is attained at $60 \mathrm{ml}$ of sulfuric acid, which was used in the remaining work. 


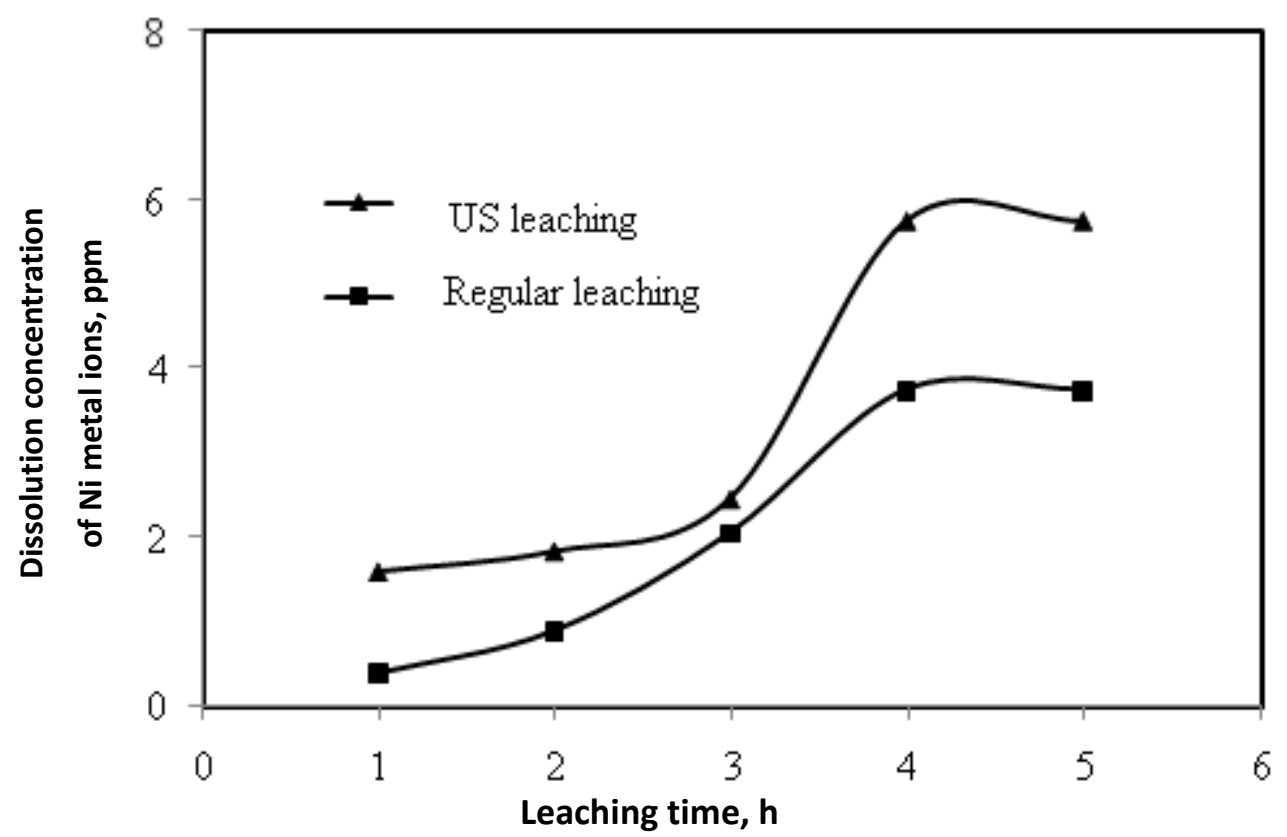

Figure 3. Effect of leaching time on Ni dissolution. Sulfuric acid concentration $5 \mathrm{M}$, solvent volume $60 \mathrm{ml}$.

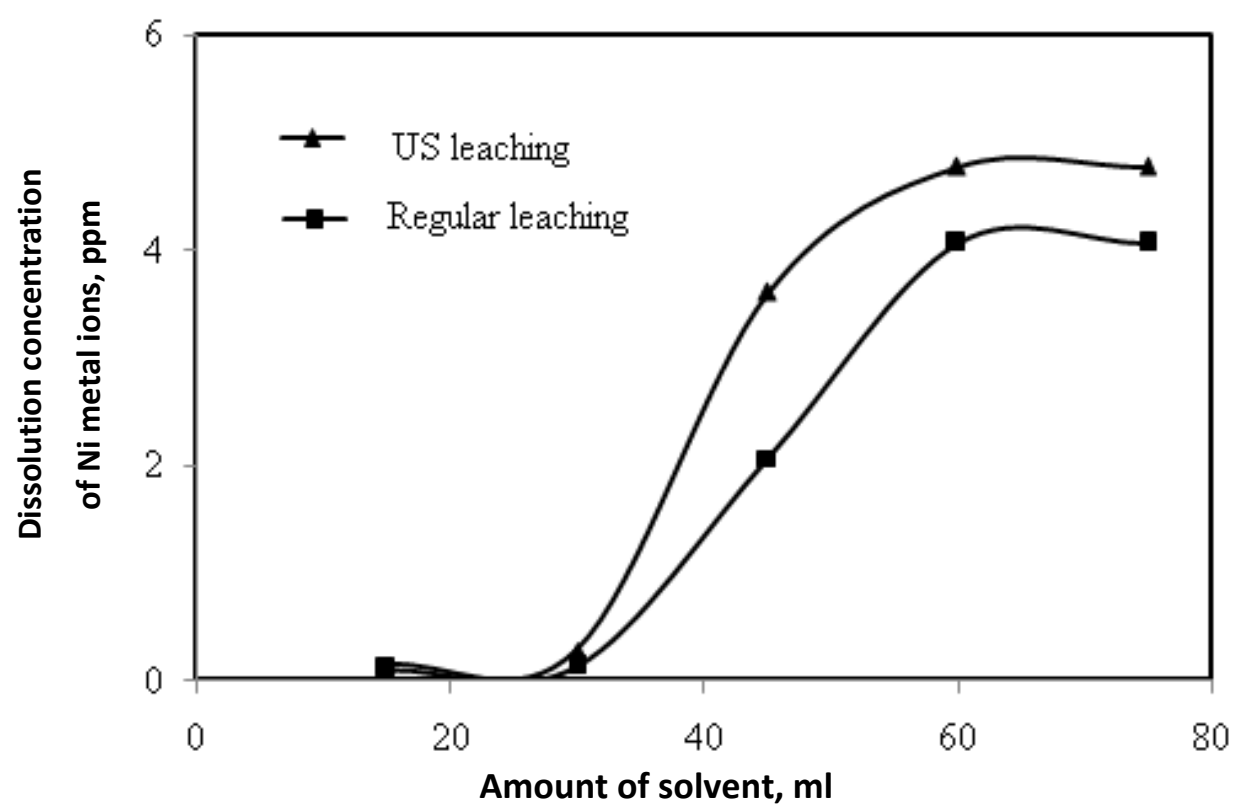

Figure 4. Effect of solvent volume on Ni dissolution. Sulfuric acid concentration $5 \mathrm{M}$, leaching time $4 \mathrm{~h}$

Comparing of dissolution concentrations of nickel metal ions at regular and ultrasonically assisted leaching shows that ultrasonically assisted leaching of spent battery enhanced the recovery of nickel metal ions. This can be due to its advantages such as the local temperature and pressure produced during the cavitation, improved convective motion and provided energy, what all facilitate dissolution of metals. The major reason for incorporation of ultrasounds during leaching is the cavitation, since the ultrasound causes formation of microscopic bubbles and subsequent implosion what reduces the size of particles. The reduced particle size provides larger surface area for an improved diffusion to occur.

\section{Ultrasonic leaching followed by electrodeposition of metal}

The leachate from regular and ultrasonically assisted leaching was used to recover nickel metal by electrodeposition. The current density was varied from $2 \mathrm{~A} \mathrm{dm}^{-2}$ to $8 \mathrm{~A} \mathrm{dm}^{-2}$. The effect of an 
increase in current density on metal recovery is shown in Figure 5. The sample of electrolyte was analyzed with the aid of AAS to identify the concentration of nickel metal ions. The concentration of nickel metal ions decreases as the electrolysis is performed, thus indicating the deposition of nickel on the surface of cathode. Maximum recovery efficiency is observed at the current density of $8 \mathrm{Adm}^{-2}$.

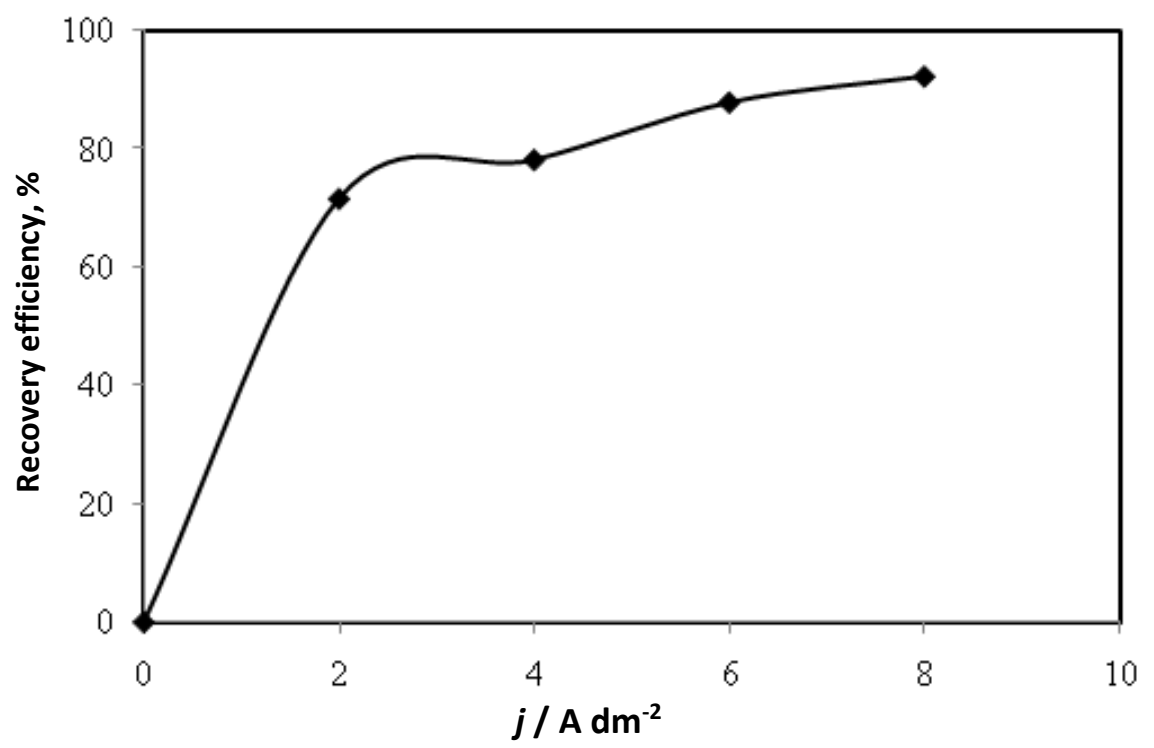

Figure 5. Effect of current density on percentage recovery of $\mathrm{Ni}$ of regular leaching leachate.

Sulfuric acid concentration $5 \mathrm{M}$; solvent volume $60 \mathrm{ml}$; leaching time $4 \mathrm{~h}$; electrolysis time $4 \mathrm{~h}$

The effect of electrolysis time on percentage recovery of $\mathrm{Ni}$ is shown in Figure 6 . The current density was maintained at $8 \mathrm{~A} \mathrm{dm}^{-2}$ for the maximum recovery of nickel. It is observed from Figure 6 that as the electrolysis time increases, Ni recovery increases up to $4 \mathrm{~h}$, beyond which no further recovery of $\mathrm{Ni}$ is observed. The recovery efficiency with ultrasonically assisted leaching and electrodeposition is $98.50 \%$ compared to regular leaching at $90.80 \%$. It is concluded that the ultrasonically assisted leaching followed by the electrodeposition has higher recovery efficiency than the regular leaching.

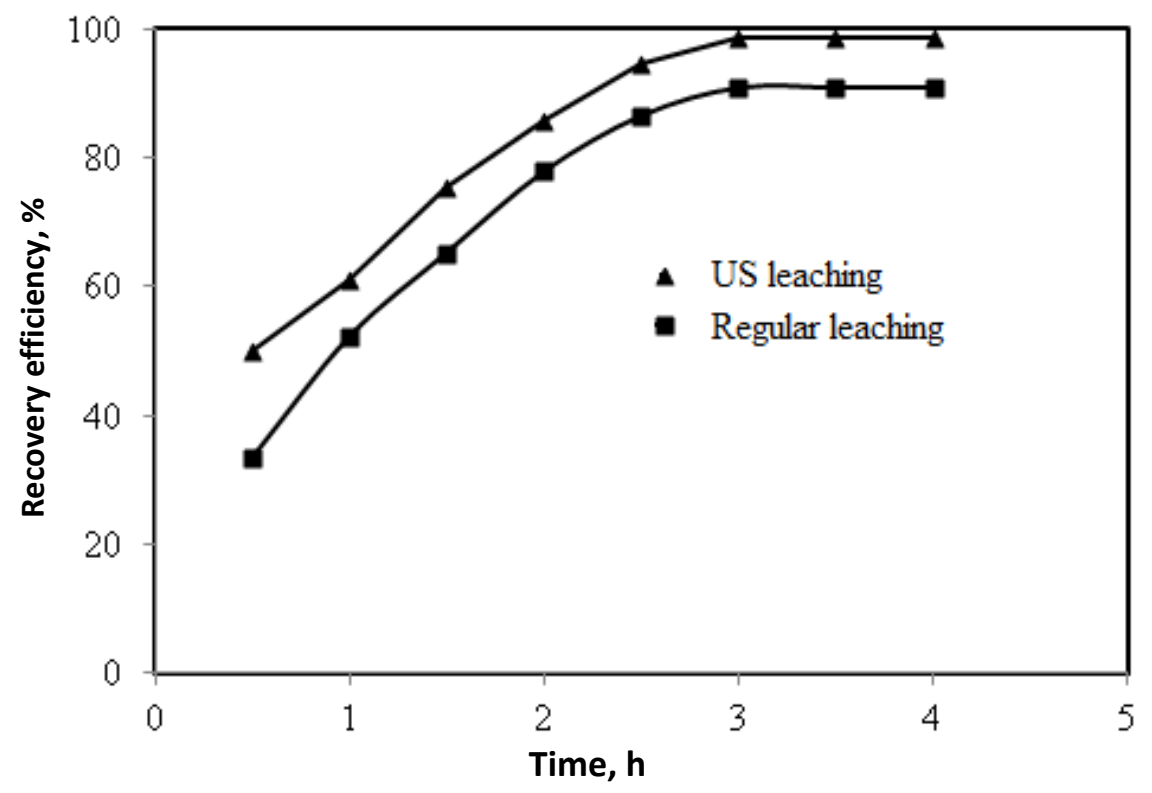

Figure 6. Effect of electrolysis time on percentage recovery of Ni. Sulfuric acid concentration $5 \mathrm{M}$, solvent volume $60 \mathrm{ml}$, leaching time $4 \mathrm{~h}$; current density $8 \mathrm{~A} \mathrm{dm}^{-2}$ 


\section{Conclusion}

This research is focused on the effects of process conditions of the regular and ultrasonically assisted leaching of $\mathrm{Ni}$ metal ions from spent $\mathrm{NiCd}$ batteries. The parameters describing process conditions, i.e. concentration of lixiviant, amount of lixiviant and leaching time were optimized. For both types of leaching, the optimized values were $5 \mathrm{M}$ for the concentration of sulfuric acid, $60 \mathrm{ml}$ for the amount of lixiviant, and $4 \mathrm{~h}$ for leaching time. The incorporation of ultrasound at $33 \mathrm{kHz}$ during the leaching process showed a certain advantage due to size reduction of particles, what resulted in more effective diffusion. The electrodeposition of nickel metal from ultrasonically assisted leachates showed the maximum recovery of nickel metal of $98.50 \%$, what is higher than $90.80 \%$ found for electrodeposition of nickel from regular leaching.

\section{References}

[1] L. E. O. C Rodrigues, M. B. Mansur, Journal of Power Sources 195 (2010) 3735-3741.

[2] C. C. B. Martha de Souza, D. Corrêa de Oliviera, J. A. S. Tenório, Journal of Power Sources 103 (2001) 120-126.

[3] L. C. Ferracin, A. E. Chácon-Sanhueza, R. A. Davoglio, L. O. Rocha, D. J. Caffeu, A. R. Fontanetti, R. C. Rocha Filho, S. R. Biaggio, N. Bocchi, Hydrometallurgy 65 (2002) 137-144.

[4] D. A. Bertuol, A. M. Bernardes, J. A. S. Tenório, Journal of Power Sources 193 (2009) 914-923.

[5] I. C. Nnorom, O. Osibanjo, International Journal of Environmental Science and Technology 6 (2009) 641-650.

[6] Y. Pranolo, W. Zhang, C. Y. Cheng, Hydrometallurgy 102 (2010) 37-42.

[7] P. Meshram, B. D. Pandey, T. R. Mankhand, Hydrometallurgy 158 (2015) 172-179.

[8] R. Oza, N. Shah, S. Patel, Society of Chemical Industries 86 (2011) 1276-1281.

[9] V. Innocenzi, F.Veglio, Journal of Power Sources 211 (2012) 184-191.

[10] K. Tanong, L. Coudert, G. Mercier, J.-F. Blais, Journal of Environmental Management 181 (2016) 95-107.

[11] M. Marafi, A. Stanislaus, Industrial Engineering Chemistry Research 50 (2011) 9495-9501.

[12] B. Avvaru, S. B. Roy, S. Chowdhury, K. N. Hareendran, A. B. Pandit, Industrial Engineering Chemistry Research 45 (2006) 7639-7648.

[13] X. Wang, C. Srinivasakannan, X.-H. Duan, J.-H Peng, D.-J., Yang, S.-H. Ju, Separation and Purification Technology 115 (2013) 66-72.

[14] L.Li, L.Zhai, X. Zhang, J. Lu, R. Chen, F. Wu, K. Amine, Journal of Power Sources 262 (2014) 380-385.

[15] C. Hazotte, E. Meux, N. Leclerc, F. Lapicque, Chemical Engineering and Processing 96 (2015) 83-93.

[16] I. Tudela, Y. Zhang, M. Pal, I. Kerr, A. J. Cobley, Surface and Coatings Technology 276 (2015) 89-105.

[17] V. E. O. Santos, V. G. Celante, M. F. F. Lelis, M. B. J. G. Freitas, Journal of Power Sources 218 (2012) 435-444.

(C)2019 by the authors; licensee IAPC, Zagreb, Croatia. This article is an open-access article distributed under the terms and conditions of the Creative Commons Attribution license (http://creativecommons. org/licenses/by/4.0/) 